\title{
ASPECTOS DE IMPORTĀNCIA PARA A VIGILÂNCIA EPIDEMIOLOGICA DA POLIOMIELITE NA CIDADE DE SÃO PAULO, BRASIL
}

Victório Barbosa *

Klaus E. Stewien**

Barbosa, V. \& STEWIEN, K. E. Aspectos de importância para a vigilância epidemiológica da poliomielite na cidade de São Paulo, Brasil. Rev. Saúde públ., S. Paulo, 14:557-68, 1980.

RESUMO: São apresentados diversos aspectos epidemiológicos da poliomielite na Capital de Sáo Paulo (Brasil). De sua análise resultaram algumas conclusồes de importância para a manutençào do controle dessa doença em nosso meio. Verificou-se a absoluta necessidade de se manter continuamente a cobertura vacinal da populacão infantil, pois a diminuição de intensidade na aplicação da vacina Sabin poderá trazer o imediato recrudescimento da doença entre nós. Após um periodo de 4 anos de controle efetivo sobre a poliomielite, no qual ocorreram, em média, 58 casos de doença paralitica por ano, foram registrados no ano de 1971195 casos. A situaşão somente voltou a ser efetivamente controlada no segundo semestre de 1975, quando os programas de imunização foram novamente incrementados. $O$ estudo mostrou que a poliomielite continua apresentando entre nós as clássicas feicōes da paralisia infantil, ocorrendo cerca de $75 \%$ dos casos nos dois primeiros anos de vida das criancas. Este fato, juntamente com a evidência de que o poliovirus do tipo 1 continua prevalecendo em nosso meio, tendo causado a grande maioria dos casos de doença paralítica nos últimos anos, indica que a epidemiologia da virose ainda não foi essencialmente alterada pelos programas de vacinação. Verificou-se, que a vacinaçẫo Sabin tem sido menos eficiente em nosso meio do que nos paises altamente desenvolvidos $e$ de clima temperado, devido à interferência de uma série de fatores epidemiológicos e operacionais. No periodo de 1970 a 1977 $8,9 \%$ dos pacientes investigados tinha recebido, no passado, 3 e 4 e mais doses de vacina oral trivalente $e$ 43,3\% tinha tomado pelo menos uma dose de vacina oral. Recomenda-se às autoridades sanitárias que o número de doses de vacina da série básica de imunização contra a poliomielite seja aumentado de três para cinco, com a finalidade de se compensar as falhas que ocorrem na prática da vacinação oral e de se poder superar o efeito antagónico dos fatores epidemiológicos desfavoráveis no controle de poliomielite em nosso meio.

Unitermos: Poliomielite, S. Paulo, Brasil. Vigilância epidemiológica.

* Do Departamento de Epidemiologia da Faculdade de Saúde Pública da USP - Av. Dr. Arnaldo, 715 - 01255 - São Paulo, SP - Brasil.

* Do Departamento de Microbiologia e Imunologia do Instituto de Cièncias Biomédicas da USP - Av. Dr. Arnaldo, 715 - 01255 - São Paulo, SP - Brasil. 
BARBOSA, V. \& STEWIEN. K. E. Aspectos de importância para a vigilância epidemiológica da poliomielite na cidade de São Paulo, Brasil, Rev. Saride públ., S. Paulo, 14:557-68, 1980.

\section{INTRODUSAO}

Nos anos que antecederam a introdução) da vacina Sabin em nosso meio, a cidade de São Paulo foi palco de grave's surtos epidèmicos de paralisia infantil, us quais culminaram com o surto de 1960, ano $\mathrm{em}$ que 794 casos de polionielite forant registrados, atingindo o coeficiente de morbidade a cifra de 20 casos por 100.000 habitantes. A exemplo do que ocorrell em outras regiōes do mundo, a realização de uma campanha de vacinação en massa na Capital de São Paulo no ano de 1962, mediante o emprego da vacina de virus vivos atenuados de Sabin, teve grande impacto sobre a epidemiologia da doença, conseguindo-se reduzir neste ano o número de casos de poliomielite para 180 . Entretanto, sendo a estrutura epidemiológica muito favorável à intensa circulação dos virus da poliomielite em nossa comunidade, o efetivo controle da doença na cidade de São Paulo somente foi alcançado quando intensas campanhas de vacinação em massa foram reiniciadas en 1966, sendo continuadas, além da vacinação de rotina, durante o ano de 1967. Barbosa (1968)2, ens trabalho anterior, comentando o controle da poliomielite no municipio de São Paulo, fez recomendaçós no sentido de se manter a doença sob efetivo controle, que então resultaram na adoção sistemática, por parte das nossas autoridades sanitárias, de um duplo esquema de imunização contra a poliomielite.

Este esquema, o qual se fundamenta nas características sócio-econômicas e sanitárias da Capital, sobretudo nas de sua periferia, então consideradas altamente desfavoráveis à manutenção do controle alcançado, recomendava a aplicação intensiva e adequada de novas doses de vacina Sabin à população susceptivel, mediante a realização de campanhas de vacinação em massa, corretamente intercaladas, bem como pela vacinação diária e rotineira pelas numerosas unidades sanitárias locais. Com a aplicação deste esquema foi possivel manter a poliomielite sob efetivo controle na Capital de São Paulo durante os anos de 1967 a 1970.
Entretanto, eln decorrência de uma sèrie de fatores, entre us quais se destaca a faita de educação sanitária da maioria de seus habitantes, parcelas ponderáveis de crianças não participaram dos programas de vacinação. Em consequência disso, um contingente apreciável de crianças, apesar dos sucessivos apelos das autoridades sanitárias, deixou de receber a vacina Sabin no ano de 1970), dando origem a formação de lacunas no estado imunitário da população infantil e, assim, tivemos, enı 1971, recrudescimento do número de casos da doença, quando 195 casos de paralisia infantil foram registrados, correspondendo a um coeficiente de morbidade de 3,1 por 100.000 habitantes (Barbosa e Stewien, 1975)" Nos anos seguintes os programas de imunização foram profundamente afetados na Capital de São Paulo pela problemática da epidemia de meningite, ocasionada pelos tipos A e $C$ do meningococo, e que motivou intensa ação de combate à doença por parte dos órgãos públicos. A campanha de vacinação em massa, em que cerca de 10 milhões de pessoas foram vacinadas contra a meningite no periodo de 4 dias nesse municipio, em abril de 1975, surtiu ótimos resultados e teve grande impacto sobre a população local, a qual, já acreditando na eficácia e no valor de vacinas como agentes profiláticos, passou a participar intensivamente dos programas de imunização contra a poliomielite. Grande parte de sua faixa etária susceptível recebeu a vacina Sabin a partir do ano de 1975, quando campanhas de vacinação em massa puderam ser realizadas em periodos de um dia e com grande facilidade de acesso a cerca de 500 postos de vacinação estratégicamente instalados em todo o município, 3 vezes ao ano. Com isso, a poliomielite pôde ser novamente colocada sob efetivo controle.

O presente trabalho, teve o intuito de propor sugestões que visem o aprimoramento das medidas profiláticas contra a doença em nosso meio. 
BARBOSA, V. \& STEWIEN, K. E. Aspectos de importância para a vigilância epidemiológica da poliomielite na cidade de São Paulo, Brasil, Rev. Saüde pübl., S. Paulo, 14:557-68, 1980.

\section{MATERIAL E METODOS}

Foi feita revisão de determinados aspectos epidemiológicos da poliomielite na capital de São Paulo, para poder localizar c discutir, em detalhes, as suas causas.

Os dados sobre a população do municipio de São Paulo, utilizados para o cálculo dos coeficientes de morbidade por poliomielite, quer os anuais, quer os por idade e os dos Distritos Sanitários do Municipio, foram os oficiais do Departamento de Estatística do Estado. Os dados dos casos confirmados de poliomielite e os de vacinação antipoliomielítica são provenientes do Serviço de Epidemiologia do Departamento Regional de Saúde da Grande São Paulo da Secretaria de Estado da Saúde do Governo de São Pauln. A composiçâo dos treze Distritos Sanitários do município de São Paulo e a seguinte: 1. BELENZINHO: Sub-distritos de Belenzinho, Brás, Moóca, Pari e Alto da Moóca; 2. SANTA CECilla: Sub-distritos de Santa Cecília, Perdizes, Barra Funda, Cerqueira Cesar, Bela Vista, Bom Retiro e Cambuci; 3. VILA MARIANA: Sub-distritos de Vila Mariana, Indianópolis, Ibirapuera e Jardim Paulista; 4. VILA MARIA: Sub-distritos de Vila Maria e Vila Guilherme; 5. PENHA DE FRANÇA: Sub-distritos de Penha de França, Cangaiba, Tatuapé, Vila Formosa e Vila Matilde; 6. SAO MIGUEL PAUlista: Distritos de São Miguel Paulista, Itaquera, Ermelino Matarazzo e Guaianazes; 7. JABAQUARA: Sub-distritos de Jabaquara e Saúde; 8. VILA PRUDENTE: Sub-distritos de Vila Prudente e Ipiranga; 9. LAPA: Sub-distritos de Lapa, Pirituba e Jaguara e os Distritos de Perus e Jaraguá; 10. SANTO AMARO: Sub-distritos de Santo Amaro e Capela do Socorro e o Distrito de Parelheiros; 11. BUTANTA: Sub-distritos de Butantã, Pinheiros, Vila Madalena e Jardim América; 12. NOSSA SENHORA DO Ó: Sub-distritos de Nossa Senhora do Ó, Casa Verde, Brasilândia, Vila Nova Cachoeirinha e Limão; 13. TUCURUVI: Sub-distritos de Tucuruvi e Santana (Fig. 1).

\section{RESULTADOS}

Os coeficientes de morbidade da poliomielite e sua relação com o número de doses de vacina Sabin distribuidas à população infantil da cidade de São Paulo são apresentados para 0 periodo de 1960 a 1977 na Figura 2. Verifica-se através do seu exame, que durante esse período a incidência da doença caiu dramaticamente no ano de 1967, quando se registrou um coeficiente de 0,6 por 100.000 habitantes, correspondente a 32 casos. Este ano marcou o inicio do controle da poliomielite entre nós (Barbosa, 1968)2. Desde então os coeficientes de morbidade permaneceram baixos durante o periodo de três anos consecutivos, oscilando en torno de $1: 100.000$ (Barbosa e Stewien, 1975) ${ }^{3}$. Entretanto. a incidencia da doença sofreu novo aumento no ano de 1971, permanecendo relativamente elevada até 1975 , como mostram os coeficientes de morbidade, que variam entre " minimo de 1,8 (1972) e máximo de 3,8 (1973). Este fato mostrou que a poliomielite tinha escapado ao sell efetivo controle na Capital de São Paulo. No período de 1971 a 1975 foram registrados, em média, nada menos do que 200 casos de poliomielite, por ano, o que evidentemente contrasta com a média de 58 casos anuais do periodo de 1967 a 1970 , e com os 47 e 28 casos ocorridos em 1976 e 1977, respectivamente.

A Figura 2 também nostra a existência de uma estreita relação entre os coeficientes de morbidade da poliomielite e o número de doses de vacina Sabin administradas no mesmo período. Observa-se que os coeficientes apresentaram valores baixos sempre que o número de doses de vacina foi elevado. Servem de exemplo os anos de $1967,68,69,76$ e 77 , quando cerca de 2 milhões de doses anuais de vacina oral foram distribuídas à população infantil de São Paulo. Os coeficientes mostraram-se relativamente elevados nos anos de 1973, 74 e 75 , período em que apenas 1 milhão de doses anuais de vacina foram aplicadas. 


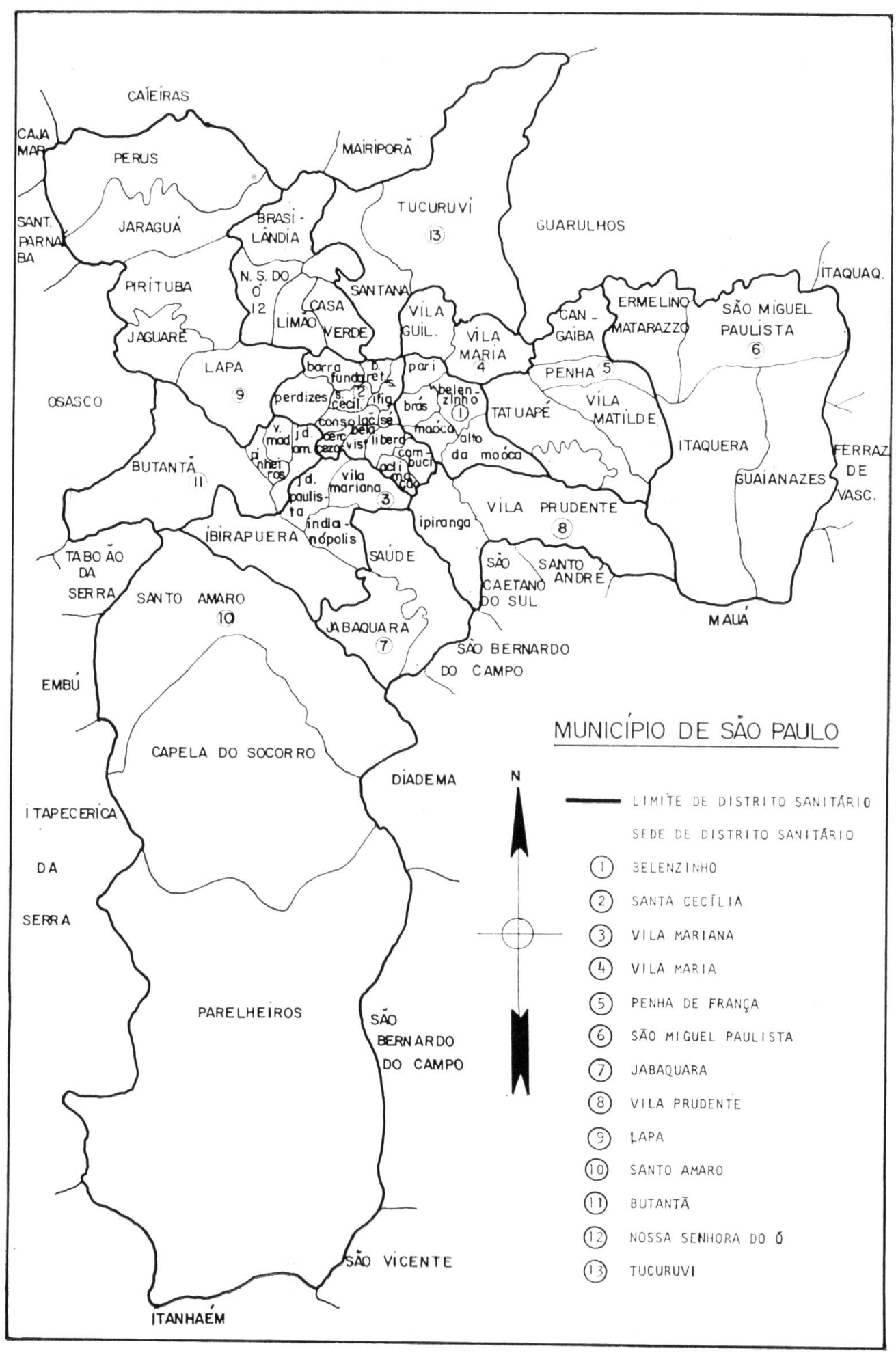

Fig. 1 - Distritos Sanitários, por distritos e sub-distritos de paz, do municipio de São Paulo - 1977.

Fonte: Departamento Regional de Saúde da Grante São Paulo. 
BARBOSA, V. \& STEWIEN, K. E. Aspectos de importancia para a vigilancia epidemiologica da poliomielite na cidade de São Paulo, Brasil, Rev. Saúde públ., S. Paulo, 14:557-68, 1980.

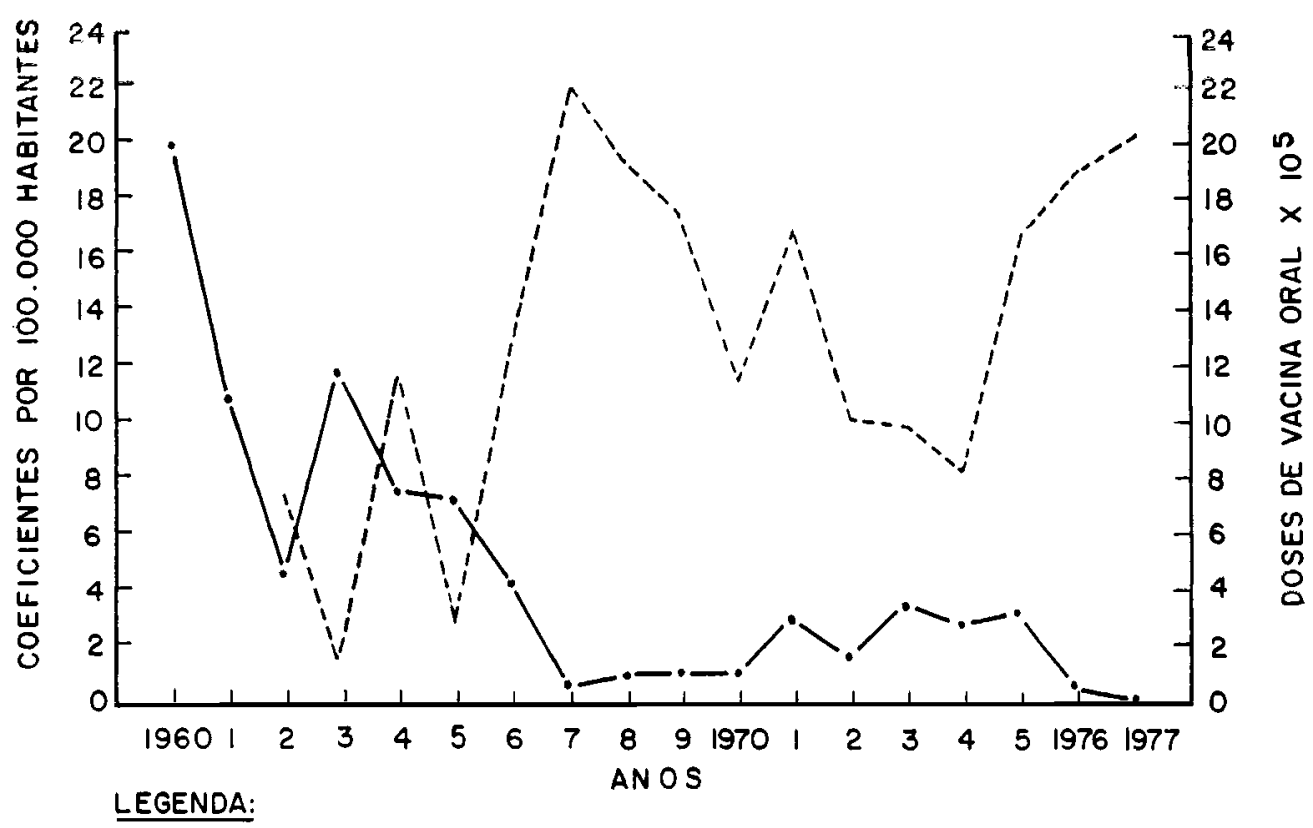

- Morbidade por Poliomialite

.... Número de doses dé vacina oral

Fig. 2 - Morbidade por poliomielite paralítica e número de doses de vacina oral trivalente de Sabin no municipio de São Paulo - 1960 a 1977.

Fonte: Departamento Regional de Saúde da Grande São Paulo.

Verificamos que o biênio de 1970 e 1971 parece fugir à regra apresentada, de vez que não se verifica a relação entre o número de doses de vacina e a incidência da doença, mas a situação se explica pela interação de dois fatores. A baixa incidência da doença no ano de 1970 decorreu da cobertura vacinal da população infantil nos anos anteriores, ou seja, de 1967 a 1969. Em consequiência, a maioria das crianças estava satisfatoriamente protegida naquele ano. Tendo sido deficiente a vacinação oral em 1970, houve no ano seguinte acúmulo de susceptiveis. Isto motivou um rápido e substancial aumento no número de casos de poliomielite no ano de 1971. De fato, 149 dos 195 casos ocorreram nos meses de janeiro a abril desse ano. Em face desta situação, as autoridades sanitárias intensificaram os programas de vacinação Sabin, sendo distribuidas naqueles meses aproximadamente 700.000 doses de vacina, o que corresponde a $40 \%$ do total de doses aplicadas no ano de 1971, ou seja, 1.704.802. A ocorrência de uma epidemia de maiores proporçōes pôde ser assim contida.

Como mostra a Figura 2, o coeficiente de morbidade do ano de 1975 é relativamente elevado, ou seja, de 3,1 por 100.000 habitantes, e não reflete a grande quantidade de vacina Sabin distribuida naquele ano, isto é, cerca de 1.700 .000 doses. Isto se explica pelo fato de que a maior parte desta quantidade (1.100.811 doses de vacina) foi administrada no último trimestre daquele ano. Ficam assim esclarecidas as exceções da regra por nós antes apresentada. 
BARBOSA, V. \& STEWIEN. K. E. Aspectos de importância para a vigilância epidemiológica da poliomielite na cidude de São Paulo, Brasil, Rev. Saúde públ, S. Paulo, 14:557-68. 1980.

Na Tabela 1 é apresentada a distribuição dos casos de poliomielite registrados no período de 1967 a 1977 na Capital de São Paulo, por grupos etários. Conforme se observa, a ocorrência de casos de doença ¿ maior entre as crianças dos dois primeiros anos de vida, alcançando $75.3 \%$ $(39,4 \%+35,7 \%)$. A Figura 3 ilustra ainda melhor este fato, mostrando que os coeficientes de morbidade dos grupos etários de $0-1$ e 1 - 2 anos destacam-se dos demais.

Os resultados do diagnóstico laboratorial da poliomielite são apresentados para os anos de 1972 a 1976 na Tabela 2 . O isolamento e a identificação de poliovírus
T A B E L A 1

Distribuição etária dos casos de poliomielite. oficialmente registrados nos 11 últimos anos na Capital de São Paulo. 1967 - 1977.

\begin{tabular}{|c|c|c|c|}
\hline \multirow{2}{*}{\multicolumn{2}{|c|}{$\begin{array}{l}\text { Idade } \\
\text { (anos) }\end{array}$}} & \multicolumn{2}{|c|}{ Casos de Poliomielite } \\
\hline & & $N^{\circ}$ & $\%$ \\
\hline \multicolumn{2}{|r|}{$<1$} & 514 & 39,4 \\
\hline \multicolumn{2}{|r|}{1} & 466 & 35,7 \\
\hline \multicolumn{2}{|r|}{2} & 192 & 14,7 \\
\hline \multicolumn{2}{|r|}{3} & 61 & 4.7 \\
\hline \multicolumn{2}{|r|}{4} & 30 & 2,3 \\
\hline 0 & -5 & 1.263 & 96,8 \\
\hline 5 & -10 & 36 & 2.7 \\
\hline 10 & -15 & - & - \\
\hline \multicolumn{2}{|r|}{$\geqslant 15$} & 6 & 0,5 \\
\hline \multicolumn{2}{|r|}{ Total } & 1.305 & 100,0 \\
\hline & $\begin{array}{l}\text { Departai } \\
\text { Grande }\end{array}$ & $\begin{array}{l}\text { Regional } \\
\text { Paulo. }\end{array}$ & Saúde \\
\hline
\end{tabular}

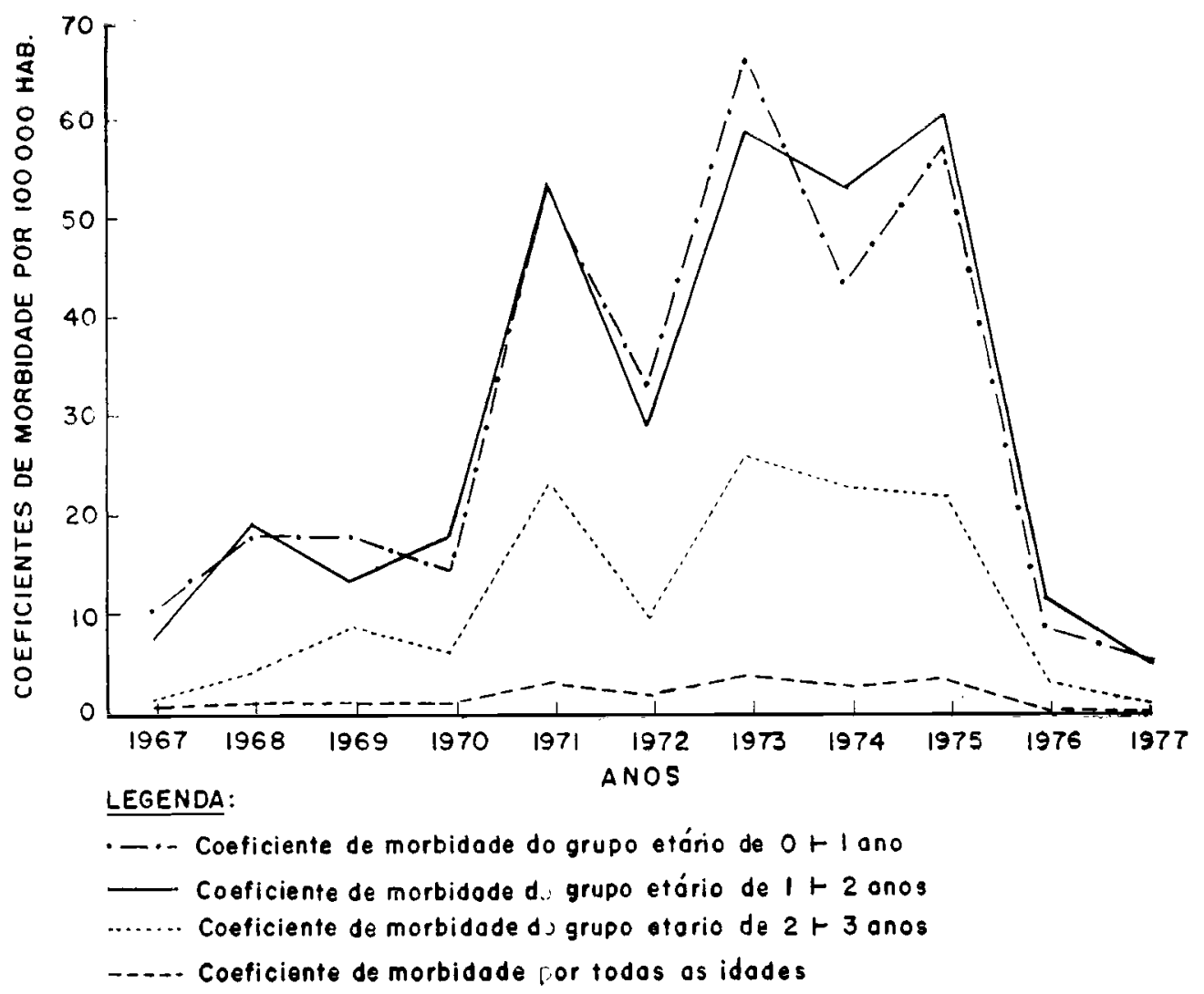

Fig. 3 - Coeficientes anuais de morbidade por poliomielite paralitica segundo os grupos etários de menos de 1, 1 e 2 anos e por todas as idades no municipio de São Paulo - 1967 a 1977.

Fonte: Departamento Regional de Saúde da Grande Sâo Paulo. 
BARBOSA, V. \& STEWIEN, K. E. Aspectos de importancia para a vigilância epidemiológica da poliomielite na cidade de São Paulo, Brasil, Rev. Saúde púbt., S. Paulo, 14:557-68, 1980.

TA B E L A 2

Distribuição dos casos de poliomielite, por tipos de rîrus, no münicípio de são paulo. $1972-1976$

\begin{tabular}{|c|c|c|c|c|c|c|c|c|c|c|c|c|}
\hline \multirow{2}{*}{ Virus } & \multicolumn{2}{|c|}{1972} & \multicolumn{2}{|c|}{1973} & \multicolumn{2}{|c|}{1974} & \multicolumn{2}{|c|}{1975} & \multicolumn{2}{|c|}{1976} & \multicolumn{2}{|c|}{ Total } \\
\hline & No & $\%$ & $\mathrm{No}$ & $\%$ & $\mathrm{~N}$ & $\%$ & $\mathrm{~N}^{\circ}$ & $\%$ & $\mathbf{N}^{0}$ & $\%$ & & $r / s$ \\
\hline Polio 1 & 82 & $(96.5)$ & 164 & $(97,6)$ & 137 & $(93,8)$ & 199 & $(93,0)$ & 35 & $(92,1)$ & 617 & $(94,8)$ \\
\hline Polia 2 & 1 & $(1,2)$ & 2 & $(1.2)$ & - & $(\rightarrow)$ & 3 & $(1,4)$ & - & $(-)$ & 6 & $(0.9)$ \\
\hline Polio 3 & 2 & $(2.3)$ & 2 & $(1.2)$ & 9 & $(6.2)$ & 12 & $(5,6)$ & 3 & $(7,9)$ & 28 & $(4.3)$ \\
\hline Sub-total & 85 & 74.6 & 168 & 68,9 & 146 & 71.9 & 214 & 88,8 & 38 & 79,2 & 651 & 76,6 \\
\hline $\begin{array}{l}\text { Não foi } \\
\text { isolado } \\
\text { vírus }\end{array}$ & 29 & 25.4 & 76 & 31.1 & 57 & 28,1 & 27 & 11.2 & 10 & 20,8 & 199 & 23,4 \\
\hline Total & 114 & 100,0 & 244 & 100,0 & 203 & 100,0 & 241 & 100.0 & 18 & 100,0 & 850 & 100,0 \\
\hline
\end{tabular}

FONTE: Departamento Regional de Saúde da Grande São Paulo.

( ) $=$ Percentagens sobre o total de virus isolados.

se deu em 651 dos 850 casos examinados, ou seja, em $76,6 \%$. Esta taxa de isolamento pode ser considerada satisfatória, levandose em conta que o Instituto Adolfo Lutz, responsável pelo diagnóstico, não teve a seu dispor culturas de células primárias de rim de macaco, sendo os isolamentos feitos apenas em culturas de linhagens continuas (Vero e HeLa), de sensibilidade menor. Os resultados mostram a predominância do poliovirus do tipo 1, tendo este tipo sido responsável pela elevada taxa de 94,8\% dos casos examinados, com isolamento positivo. A ele se segue o poliovírus do tipo 3 , isolado em apenas $4,3 \%$ dos casos investigados. O poliovírus do tipo 2 foi isolado em raras ocasiōes, ficando sua frequência ahaixo de $1 \%$.

$\mathrm{Na}$ Tabela 3 encontram-se classificados os casos de poliomielite segundo o histórico vacinal dos pacientes, sempre que foi possível obter essa informação. O exame destes casos não revelou nenhum que fosse associado à vacinação Sabin, durante todo o período de 1970 a 1977. Stewien e Lacerda
TABEL 3

Distribuiçăo dos casos de poliomielite, segundo o número de doses de vacina Sabin recebidas no passado. São Paulo, 1970 - 1977.

\begin{tabular}{|c|c|c|}
\hline Ny de doses & Casos de & Poliomielite \\
\hline Vacina Sabin & No & $\%$ \\
\hline 0 & 441 & 56,7 \\
\hline 1 & 178 & 23,0 \\
\hline 2 & 89 & 11.4 \\
\hline 3 & 60 & 7,7 \\
\hline 4 e mais & 9 & 1,2 \\
\hline Total & 777 & 100,0 \\
\hline $\begin{array}{l}\text { Departam } \\
\text { Grande }\end{array}$ & $\begin{array}{l}\text { Regional } \\
\text { Paulo. }\end{array}$ & de Saúde \\
\hline
\end{tabular}

(1977) 14,1:;, realizando estudos sobre marcadores genéticos de estirpes de poliovirus isoladas de pacientes anteriormente vacinados, mostraram que as propriedades destas eram diferentes das estirpes vacinais de Sabin. Contudo, é preciso ressaltar o ele- 


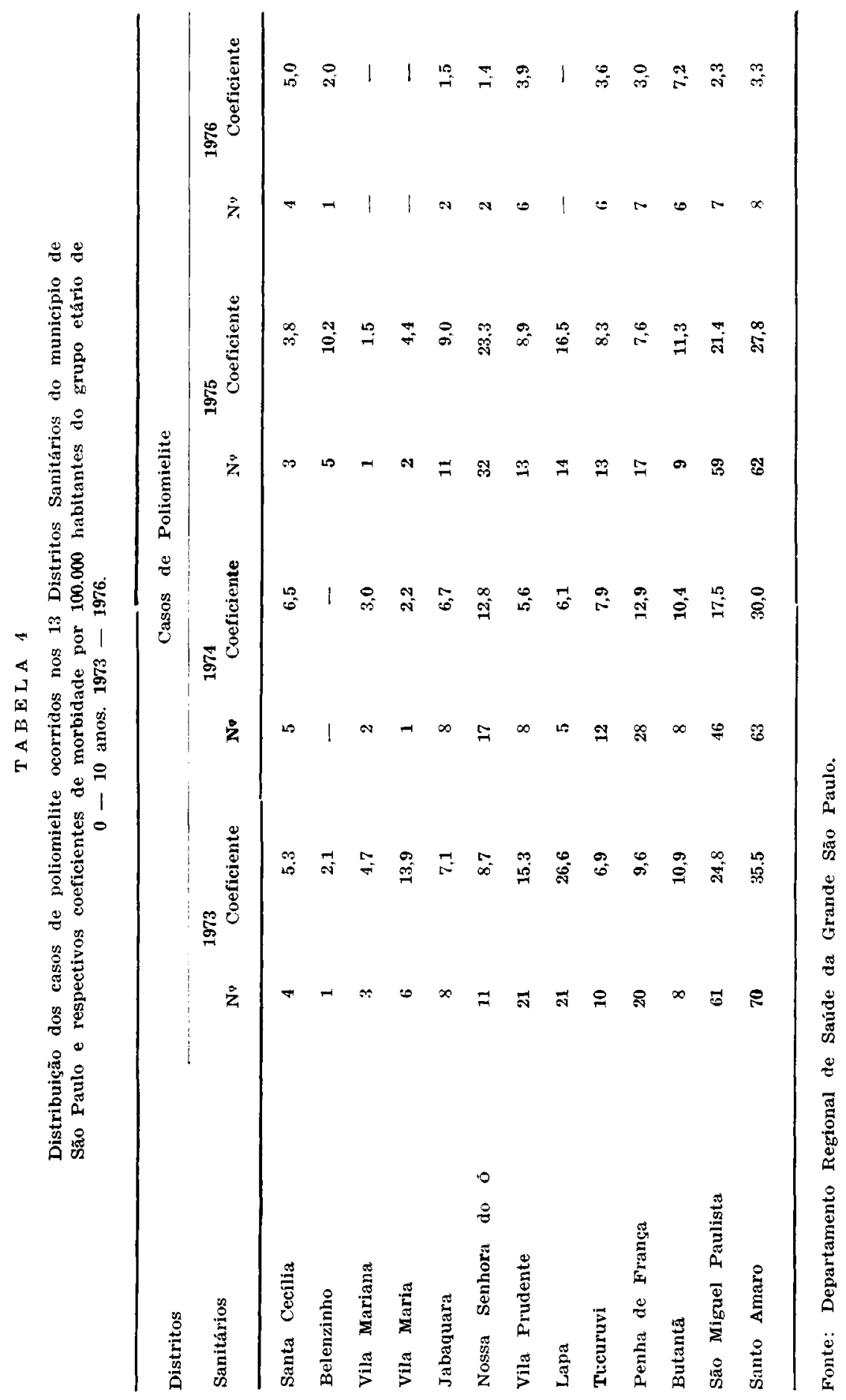


BARBOSA, V. \& STEWIEN, K. E. Aspectos de importância para a vigiláncia epidemiológica da poliomielite na cidade de São Paulo, Brasil, Rev. Saúde públ., S. Paulo, 14:557-68, 1980.

vado número de pacientes que tinham sido anteriormente vacinados. Verifica-se que nada menos do que $8,9 \%$ dos pacientes tinha recebido, no passado, 3 e 4 e mais. doses de vacina e $43,3 \%$ tinha tomado pelo menos 1 dose da vacina oral trivalente. Esta situação não mostrou melhoras ao longo do periodo examinado.

Finalmente, é apresentada na Tabela 4 a incidência da poliomielite nos diferentes Distritos Sanitários da Capital, durante o periodo de 1973 a 1976. Nota-se que os coeficientes de morbidade do grupo etário de $0-10$ anos foram geralmente mais elevados naqueles distritos localizados na periferia da cidade, onde se encontra a maior parte da população de baixo nível sócio-econômico e sanitário.

\section{DISCUSSAO}

Os resultados apresentados no presente trabalho sem dúvida mostram que a diminuição de intensidade na aplicação da vacina Sabin à população infantil da cidade de São Paulo poderá trazer o imediato recrudescimento do número de casos de poliomielite em nosso meio. Isto ficou particularmente claro en 1971, quando o coeficiente de morbidade da poliomielite sofreu um aumento da ordem de 4 vezes, em comparação com a média dos coeficientes registrados no periodo de 1967 a $1970 . \mathrm{Na}$ Figura 2 vimos que os coeficientes então permaneceram relativamente elevados durante um periodo de cinco anos, voltando a baixar somente quando os programas de vacinação foram novamente intensificados no Municipio a partir do último trimestre de 1975.

Fica assim evidente a absoluta necessidade de se manter continuamente a cobertura vacinal da população infantil, o que deverá ser conseguido através de programas de imunização intensivos e sistemáticos. A rápida perda do controle sobre a doença, antes verificada, resulta da interação de uma série de fatores epidemiológicos e operacionais, que ainda prevalecem em nosso meio. Dentre os primeiros, ressaltamos a grande densidade e o intenso crescimento populacional, o baixo nivel sócio-econômico da maioria dos habitantes, a estrutura sanitária em geral precária, o clima sub-tropical, o confinamento das massas populacionais e os freqüentes movimentos migratórios que são observados entre os diferentes distritos e sub-distritos da Capital e entre esta última e o interior do Estado de São Paulo, além de outras regiōes do pais. Em seu conjunto, estes fatores favorecem de sobremaneira a circulação dos poliovirus "selvagens", aumentando deste modo o número de infecçōes e de casos de doença, sempre que se formam lacunas no estado imunitário da população 1,12. Esta situação é agravada pelas precárias condições operacionais que ainda persistem em grande parte das unidades sanitárias da Capital, porquanto estas se manifestam negativamente na eficiência da vacinação oral em nosso meio.

A ocorrência da maioria dos casos de doença nos primeiros anos de vida das crianças mostra que a poliomielite ainda continua apresentando entre nós as clássicas feições da paralisia infantil ( $\mathrm{Ta}$ bela 1) ${ }^{1,2, i, 8}$. Este fato, juntamente com aquele que evidencia a predominância do poliovirus do tipo 1 na determinação dos casos de doença paralitica, indica que a epideniologia da poliomielite não foi essencialmente alterada em nosso meio pelos programas de vacinação. Nos paises em que tal se verificou, a doença passou a ser causada pelos três tipos de poliovirus em proporções aproximadamente iguais, depois de atingido o controle sobre a virose 6,\%. Isto mostra, também, que novos esforços serão necessários para se atingir idêntica situação na cidade de São Paulo.

Os resultados do presente trabalho mostram que especial atenção deverá ser dedicada pelas nossas autoridades sanitárias à região periférica da cidade, porquanto ali se formaram, no passado, os maiores focos 
BARBOSA, V. \& STEWIEN, K. E. Aspectos de importancia para a vigiláncia epidemiológica da poliomielite na cidade de São Paulo, Brasil, Rev. Saúde públ., S. Paulo, 14:557-68, 1980.

da poliomielite, fato esse que motivou a realização de considerável número de campanhas de vacinação em massa para conter a doença sob controle. Como vimos na Tabela 4, os lugares mais atingidos foram: São Miguel, Lapa, N. Senhora do ó e Santo Amaro. Em inquérito realizado em uma amostra representativa dos escolares do 1 \% grau da rede da Prefeitura Municipal de São Paulo, pôde ser mostrado que aprox:madamente a metade das crianças de mães analfabetas e mais da metade das crianças que habitam em favelas e cortiços não tinham completado a série básica de 3 doses de vacina oral 4. Isto mostra que maiores esforços deverão ser dirigidos à Zona Periférica da cidade.

A vigilância epidemiológica deve ser mantida dentro de um esquema rigido para que possam ser descobertas e corrigidas todas as falhas que ocorrem na prática da vacinação oral em nosso meio e que contribuem para reduzir a sua eficiência. Conforme vimos anteriormente na Tabela 3 , é grande o número de pacientes paralíticos que tinham sido vacinados contra a poliomielite com até 4 doses de vacina. Podemos afirmar que fato semelhante nunca foi observado nos países altamente desenvolvidos $7,8,10$. Com a finalidade de encontrar as causas deste fenômeno, foi realizada série de investigações em. nosso meio. $\mathrm{Em}$ dois inquéritos soro-epidemiológicos realizados na Capital de São Paulo, foi possivel verificar que a prevalência de anticorpos protetores contra os três tipos de poliovirus era relativamente baixa nas crianças das camadas pobres da população, ficando o estado imunitário dos diferentes grupos etários examinados geralmente muito aquém do limite mínimo desejável de $75 \%$ de triplo-imunes, mesmo naqueles grupos de crianças que receberam 3 doses de vacina oral trivalente $3,4,13,15$. Níveis de imunidade satisfatórios somente foram observados naqueles grupos de crianças que tinham recebido 5 e mais doses de vacina Sabin.
Em recente estudo sobre a resposta imunitária à vacina oral, pudemos mostrar que, em condições de vacinação bem controladas, um nivel de imunidade de $75 \%$ foi alcançado contra os três tipos de poliovirus, após a administração de 3 doses de vacina oral trivalente ${ }^{5}$. Este trabalho confirma o resultado de outra investigação anteriormente realizada ${ }^{11}$. Verificou-se, desta forma, que existe ampla margem de diferença entre os resultados de imunidade observados nestes trabalhos $e$ aqueles dos inquéritos soro-epidemiológicos anteriormente referidos, mostrando que os programas de vacinação oral levados a efeito na cidade de São Paulo conseguiram somente com $5 \mathrm{do}$ ses de vacina o que se consegue com 3 doses de vacina em condições operacionais benı controladas. Portanto, se considerarmos que um nivel de imunidade em torno de $75 \%$ de triplo-imunes é o mínimo necessário para se manter a poliomielite sob efetivo controle na Capital de São Paulo e levarmos en conta que as condições operacionais existentes nas unidades sanitárias estão longe de corresponder às de uma experiência cientifica, é preciso reconhecer que 3 doses de vacina Sabin não são suficientes para se imunizar adequadamente a nossa população infantil.

De tudo o que foi exposto, os autores recomendam que o numero de doses de doses de vacina da série básica de imunização oral contra a poliomielite seja aumentada de três para cinco, com a finalidade de se compensar as falhas que ocorrem na prática da vacinação e de se poder superar os efeitos antagônicos dos fatores epidemiológicos desfavoráveis ao controle da poliomielite em nosso meio. A fim de se evitar a formação de lacunas de imunidade em nossa população infantil e o conseqüente aparecimento de focos de doença, é absolutamente necessário que a série básica de imunização seja efetivamente iniciada de acordo com o calendário de vacinação estabelecido, ou seja, aos 2 meses de idade das crianças. Assim sendo, a propaganda a favor da vacinação oral e os programas de 
BARBOSA, V. \& STEWIEN, K. E. Aspectos de importância para a vigilância epidemiológica da poliomielite na cidade de São Paulo, Brasil, Rev. Saúde públ., S. Paulo, 14:557-68, 1980.

educação dirigidos ao público deverão dar ênfase a essa necessidade, para que os altos benefícios da vacina Sabin sejam realmente alcançados.

Esperamos que a leitura deste trabalho continue a manter a atenção das nossas autoridades sanitárias inteiramente voltada para o problema da poliomielite no municipio de São Paulo, principalmente no sentido de, ao lado de vacinar contínua e intensivamente, e sem esmorecimento, a população infantil susceptível, como aliás o vem fazendo, aja da mesma maneira, por meio de um longo e paciente trabalho de educação sanitária no sentido de não permitir que a nossa população venha se desinteressar, a exemplo do que ocorreu no passado, pela vacinação oral dos seus filhos. Esta atitude é, sem dúvida, absolutamente necessária, pois, se tal não for feito, talvez em futuro mais próximo do que possamos imaginar, venha o município a ser atingido novamente - pelas razōes que apontamos - pela recrudescência da freqüència de casos da doença e por epidemias de poliomielite, o que é, indiscutivelmente nada desejável.

Barbosa, V. \& STEWIEN, K. E. lImportant epidemiological aspects of poliomyelitis in the city of S. Paulo, Brazil.] Rev. Saúde públ., S. Paulo, 14: $557-68,1980$.

ABSTRACT: Several epidemiological aspects of poliomyelitis in the city of S. Paulo (Brazil) are discussed and related to measures that must be taken to maintain control of this disease. Results show the need of continued vaccination of the whole infant population, because a decrease in vaccination may permit an upraise of the disease. During four years of tight control, 58 new cases were registered per year. After that, in 1971, 195 cases appeared. Only in the second half of 1975, when immunization programs were again improved, was the situation controlled. This study shows that poliomyelitis still acts in the classical mode in that about $75 \%$ of the cases occur in children two years old or under. This, plus evidence that type 1 poliovirus is the type prevalent in $S$. Paulo, strengthens the idea that the epidemiology of this viral illness has not been essentially changed by the vaccination programs. Another finding is that the Sabin vaccine has been less efficient in our environment than in developed countries with temperate climates. This is due to epidemiological factors and operational conditions. In 1970-1977, 8.9\% of the cases had received three, four, or more doses of the trivalent oral vaccine, and $43.3 \%$ had received at least one dose of the oral vaccine. The recommendation is herewith made that the number of doses of the basic series for immunization against poliomyelitis be increased from three to five in order to counterbalance mishaps in the act of oral vaccination and our environment's difficulties related with the epidemiology of the disease.

Uniterms: Poliomielitis, S. Paulo, Brazil. Epidemiologic surveillance. 
BARBOSA, V. \& STEWIEN, K. E. Aspectos de importancia para a vigilancia epidemiológica da poliomielite na cidade de São Paulo, Brasil, Rev. Saúde públ., S. Paulo, 14:557-68, 1980.

\section{REFERENCIAS BIBLIOGRAFICAS}

1. BARBOSA, V. Contribuisäo para o conhecimento da epidemiologia da poliomielite no municipio de são Paulo. São Paulo, 1963. [Tese de Doutoramento Faculdade de Higiene e Saúde Pública da USP].

2. BARBOSA, V. Estado atual da poliomielite no município de Säo Paulo. Rev. Saúde públ., S. Paulo, 2:68-80, 1968.

3. BARBOSA, V. \& STEWIEN, K. E. Estado tmunitário relativo à poliomielite das crianças de $0-12$ anos, residentes no munićpio de São Paulo, Brasil e assistidas pelo Hospital Menino Jesus. Rev. Saúde públ., S. Paulo, 9:137-53, 1975.

4. BARBOSA, V. et al. Estado vacinal, tipo de habitação e nível cultural da mãe e sua relação com o estado imunitário contra a poliomielite em uma amostra de escolares do município de São Paulo. Rev. Saúde públ., S. Paulo, 9:330-7, 1977.

5. BARBOSA, V. et al. Nivel de imunidade contra a poliomielite em um grupo de crianças vacinadas de acordo com o calentário oficial de imunização (São Paulo, Brasil). Rev. Saude puibl, $\mathrm{S}$. Paulo, 12:326-32, 1978.

6. BEALE, A. J. et al. Evidence on the safety and efficacy of live poliomyelitis vaccines currently in use, with special reference to type 3 poliovirus. Bull. Wld Hlth Org., 40:925-45, 1969.

7. COCKBURN, W. C. Poliomyelitis vaccination in Tropical Countries. Advanc. exp. med, Biol., 31:223-36, 1972.

8. COCKBURN, W. C. \& DROZDOV, S. G. Poliomyelitis in the world. Bull. Wld Hlth Org., 42:405-17, 1970.

9. IMPERATO, J. P. The status of poliomyelitis in New York city. Bull. $N$. Y. Acad. Med., 52:814-29, 1976.
10. KUWERT, E. et al. Orale poliomyelitisschutzimpfung. Dtsch, Med. Wschr., 50:2505-9, 1970.

11. NEVES, W. E. et al. Vacinação antipoliomielítica, tipo Sabin, em crianças com um e três meses de idade. Rev. Inst. Med. trop. S. Paulo, 10:376-82, 1968.

12. SABIN, A. B. Poliomyelitis: accomplishments of live virus vaccine. In: International Conference on Vaccines Against Viral and Rickettsial Diseases of Man, $1 \mathrm{st}$, Washington, D. C., 1966. Washington, D. C., Pan American Health Organization, 1967. p. 171-7 (PAHO - Scient. publ., 147).

13. STEWIEN, K. E. \& BARBosA, V. Anâlise da situação da poliomielite em uma amostra de crianças de $0-10$ anos de idade na capital de São Paulo, com o auxillio de um parâmetro de rigilância epidemiológica. Rev. Saúde múbl., $\mathbf{S}$. Paulo, $11: 338-44,1977$.

14. STEWIEN, K. E. \& LACERDA, J. P. G. de Aplicação do método da comparação dos indices de neutralização à identificação intratípica de poliovírus dos tipos 1 e 3 , utilizando culturas de células Hep-2. Rev. Saude públ., $\mathrm{s}$. Paulo, 9:221-8, 1975.

15. STEWIEN, K. E. \& LACERDA, J. P. G. de Utilização da mierotécnica para a identificação sorológica intratípica de estirpes de poliovírus dos tipos 1 e 3 . Rev. Saúde públ., S. Paulo, 11:135-42, 1977.

16. STEWIEN, $\mathbf{K}$. E. et al. Niveis de imunidade contra a poliomielite em uma amostra de escolares do município de São Paulo, Brasil. Rev. Saúde públ., S. Paulo, 11:270-8, 1977.

Recebido para publicação em 20/08/1980

Aprovado para publicą̧ão em 12/09/1980 